\title{
The Dilemma of Abandoned Babies Needs a Unified Approach
}

\author{
Zarina Nalla*
}

The abandoning of babies has reached new heights in Malaysia. According to the police in Kuala Lumpur, in January 2011 alone 19 babies were abandoned nationwide of which, fortunately, 13 survived. Since 2005, the total figure is 517, of which 287 babies did not survive. During this period, 37 people have been apprehended for this crime and the police have charged 22 women and five men. Lack of information is the greatest hurdle faced by the police.

It is not possible to say conclusively that the majority of these abandoned babies belonged to Muslim Malays. This is because Indonesians, Nepalese and Burmese often look similar. A separate investigation by the police revealed that the majority of abandoned baby cases were committed by teenagers or women who gave birth out of wedlock. Again, if only 37 out of 517 were apprehended, this fact may not be conclusive.

To date, this writer has listened to and read many responses to this social dilemma that arise from different perspectives and individuals: doctors, pro-abortion activists, atheists, religious groups and their scholars, as well as politicians, who inadvertently colour their opinions with their own value systems, occupations, disciplines, prejudices, childhood socialisations etc.

\section{Is Abstinence 'Old School'?}

Most adherents of major religions such as Christianity, Islam, Buddhism, and Hinduism - and even non-religious persons who embrace their own values and codes of conduct - would feel that sexual relations should (ideally) take place within a marriage situation.

Perhaps, if a survey were to be conducted the result would be that many would think that abstinence (or late sexual debut) is the way to go. Similarly, Malaysians are supposed to uphold principles enshrined in their Rukun Negara (Malay for 'National Principles') - such as rule of law, the supremacy of the Constitution, courtesy and morality. As imperfect beings we are taught to always strive for the ideal knowing that if we aim for a perfect $100 \%$ mark we may achieve 80 or $90 \%$, but if we aim for $50 \%$ we may achieve 40 or $30 \%$.

In 2007, a non-governmental organisation in Malaysia led 250 students from five secondary schools on the Youth Abstinence Walk led by a female ethnic Chinese Member of Parliament. On 13 February 2011, the State of Selangor carried out the

* Zarina Nalla is Policy and Project Development Consultant with IAIS Malaysia. 
third series of the "Anti-Zina"1 campaign aimed at educating the Muslim community. Critics, however, voiced their concern that preaching abstinence is limiting and futile; society should not stigmatise sexual activity outside marriage but come to terms with such reality, respect the right of the individual, and teach safe sex instead.

This writer holds a different view.

Individuals - married or single - at a suitable age need to be educated about their reproductive systems within the context of values that cherish abstinence, marriage and family institutions, planned pregnancy, and family planning. Protected sex is naturally part of this curriculum, if you like, because people need to be responsible for their own bodies and need to guard themselves from diseases and unwanted pregnancies. It is thus important to contextualise safe sex. The ultimate decision whether to be sexually active, at what age, and with whom is a choice made by the individual concerned.

Hence in a perfect world, Malaysia would never have to deal with abandoned babies because every baby born to its parents would be a wanted child, legitimate or illegitimate. However, we all know this is not happening.

Policies that will bear fruit in the long-term demand that all educators, schools, parents, religious leaders, as well as public activists, teach (and keep teaching) in an inspiring non-forceful manner the values that one aspires to see in Malaysian society. We need to teach our young (and also adults) to be honest, stay loyal, value one's body, recognise sexual needs as something natural, understand how to satisfy them responsibly within the parameters of the value-system you subscribe to.

\section{Avoiding Unwanted Pregnancies: Educators Can Help}

At numerous forums one hears representatives from the authorities reiterating that the focus should be on avoiding unwanted pregnancies and not facilitating abortions after the fact. This is perfectly understandable, but it is not well accepted by pro-choice activists who feel strongly that women are custodians of their own bodies and should be in a position to abort if they choose to.

A conference once attended by this writer demonstrated how easy it is to abort in the comfort of your own home with a tablet under your tongue; there is no need to involve clinicians - just be in charge of your body!

Sounds all very well, but this writer's vote is 'yes, be in-charge of your own body and stay "baby-free" unless you want the baby'. It is unarguable that undergoing an abortion is far from pleasant and can physically (and psychologically) harm a young woman. Hence the need for safe abortions - a separate subject, which cannot be dealt with here. 
However, an unplanned pregnancy can happen and the idea of carrying the unwanted child to full term and not knowing what to do with the baby is the worst option for the mother. In such cases, what are the options presented to the woman?

Men are as much to be blamed or, in some cases, more so than women who have unfortunately been victimised. Moreover, there are marriages where the wife is dissuaded from taking protection, and the husband too does not take any effort to protect her from unwanted pregnancies, or the mother of, say, three or four who is not agreeable to having more kids is being coerced into having another baby by her husband. Men need to be educated so they don't become bullies, and women need to assert their rights using whatever 'tools' work for them: involving an elder or relative, or a penghulu kampong (Malay for 'village head'), or arranging for a doctor to speak to the husband. This writer, for instance, knows of a case where the gynaecologist called the husband and chastised him.

Religious leaders: Muslim clerics or Catholic priests, for instance, telling their students or congregations that taking protection is a sin also contribute to the current dilemma. This contributor, as a Muslim (and again based on her own interpretation and understanding) is aware of the fact that family planning is allowed in Islam and that contraceptives are not harām or forbidden.

\section{Unwanted Pregnancies: Medical Professionals and NGOs Can Help}

We all - as members of society - have collectively failed to stop Individual A from having an unwanted pregnancy: she is now expecting in her first trimester and she does not want to carry the child to full term. Where can she go for help and advice? There are teenage pregnancies due to carelessness, ignorance, rape, or even incest. Can she go to a government hospital and see if she qualifies for an abortion, perhaps explaining how she became pregnant and be advised as to the next course of action? There is thus a need for doctors and nurses to act professionally and not morally police their patients.

A pregnant woman deserves support and the child she is carrying represents a life that we cherish and want to save as much as possible. We are told that the medical fraternity is unwilling to carry out abortions when the reason calling for it falls under the 'mental' category, for instance rape victims. There is also a stigma and the tendency to judge the women. ${ }^{2}$ The solutions will vary from situation to situation; there is no 'one size that fits all'.

In a separate situation, take the scenario of a young girl who is expecting and for whatever reason will deliver the baby but does not want to care for it. She is desperate.

This writer's investigations into the matter have shown that babies at government orphanages have a sad fate; administrative inefficiency does not facilitate their quick 
adoption despite the fact that the waiting list of childless couples is long. Moreover, these centres are not well-advertised because it is a taboo.

If the baby was left in a safe place and there are signs that the person who placed him there wanted the baby to be found - for instance at a train station, in a basket with a bottle of milk, a note or with some cash - there is something less tragic about these cases. There was a recent case of a young girl who asked someone to hold her baby while she went to the bathroom and she never returned. She abandoned her baby but did not neglect the child.

When babies are found - on the brink of death - in rubbish dumps in deserted areas or flushed down the toilet then the intent may be different and the police may need to investigate further before punishing those responsible.

\section{Conclusion and Recommendations}

One appreciates the need to not condone behaviours that we feel are wrong but there is also an equally important need to not judge because that truly is solely the right of God - and God alone. There is also an obligation to help someone in need. Cultural taboos and stigmatising the young woman who is in need has already cost too many lives.

This contributor has arrived at a multi-faceted solution, one that puts into action all of the following simultaneously:

- use all tools at hand to encourage abstinence;

- teach safe sex so that unwanted pregnancies are avoided within or outside a marriage ('be responsible for your own body');

- make abortion a real option, but only for cases that qualify for it (young girls deemed mentally unprepared to undergo the pregnancy such as rape victims);

- provide real options for young mothers with unwanted babies (women who want to give up their babies but need a 'safe place' to go to) free from persecution and judgment.

The first action item above is a long-term solution that will only give results over some period of years, but as it takes effect the other more short-terms solutions may be redundant over time. However, to arrest the current crisis that we are currently facing, making known safe houses and encouraging safe sex may be the way to go.

Hence the baby-abandonment crisis requires a holistic approach from the different response centres in Malaysian society:

- NGOs, healthcare professionals, educators (parents and teachers), religious leaders, the media and - the government; 
- choices must be made available to girls and women in Malaysian society;

- teenagers, married women, migrant workers, refugees in detention centres, and prison inmates deserve our collective attention and support;

- all stakeholders and members of society need to do what they can within their own parameters or jurisdictions - without, however, imposing on others their values;

- we can only discuss and negotiate politely. Politicians can do so much manoeuvring - but doctors should behave like doctors, educators should teach. We should agree on the common ground and synchronise all efforts. This may be the best way to help ease this difficult and heart-wrenching situation in multicultural Malaysia.

\section{Notes}

1. Zinā is the Arabic term for extra- or premarital sex.

2. Malaysia's Abortion Act of 1967 was amended in 1989. The criterion for permitting abortion is when there is "risk of injury to the mental or physical health" of the pregnant woman. This is identical to the United Kingdom's amendment in 1967 where abortion is generally provided on request if the doctors are sympathetic to the woman's plight. 